\title{
Annual cycle of Antarctic baseline aerosol: controlled by photooxidation-limited aerosol formation
}

\author{
M. Fiebig ${ }^{1}$, D. Hirdman ${ }^{2}$, C. R. Lunder ${ }^{3}$, J. A. Ogren ${ }^{4}$, S. Solberg ${ }^{1}$, A. Stohl ${ }^{1}$, and R. L. Thompson ${ }^{1}$ \\ ${ }^{1}$ Department for Atmospheric and Climate Research, Norwegian Institute for Air Research, Kjeller, Norway \\ ${ }^{2}$ Swedish Meteorological and Hydrological Institute (SMHI), Norrköping, Sweden \\ ${ }^{3}$ Monitoring and Information Technology Department, Norwegian Institute for Air Research, Kjeller, Norway \\ ${ }^{4}$ Earth System Research Laboratory/Global Monitoring Division, National Oceanic and Atmospheric Administration, \\ Boulder Colorado, USA
}

Correspondence to: M. Fiebig (markus.fiebig@ nilu.no)

Received: 19 August 2013 - Published in Atmos. Chem. Phys. Discuss.: 2 September 2013

Revised: 30 January 2014 - Accepted: 31 January 2014 - Published: 27 March 2014

\begin{abstract}
This article investigates the annual cycle observed in the Antarctic baseline aerosol scattering coefficient, total particle number concentration, and particle number size distribution (PNSD), as measured at Troll Atmospheric Observatory. Mie theory shows that the annual cycles in microphysical and optical aerosol properties have a common cause. By comparison with observations at other Antarctic stations, it is shown that the annual cycle is not a local phenomenon, but common to central Antarctic baseline air masses. Observations of ground-level ozone at Troll as well as backward plume calculations for the air masses arriving at Troll demonstrate that the baseline air masses originate from the free troposphere and lower stratosphere region, and descend over the central Antarctic continent. The Antarctic summer PNSD is dominated by particles with diameters $<100 \mathrm{~nm}$ recently formed from the gas-phase despite the absence of external sources of condensible gases. The total particle volume in Antarctic baseline aerosol is linearly correlated with the integral insolation the aerosol received on its transport pathway, and the photooxidative production of particle volume is mostly limited by photooxidative capacity, not availability of aerosol precursor gases. The photooxidative particle volume formation rate in central Antarctic baseline air is quantified to $207 \pm 4 \mu \mathrm{m}^{3} /(\mathrm{MJ} \mathrm{m})$. Further research is proposed to investigate the applicability of this number to other atmospheric reservoirs, and to use the observed annual cycle in Antarctic baseline aerosol properties as a benchmark for the representation of natural atmospheric aerosol processes in climate models.
\end{abstract}

\section{Introduction}

The Antarctic continent is located as remote as possible from most anthropogenic emission sources on the planet. Despite measurable human influence, it is still suited to study atmospheric processes as unaltered as possible by human activity. The quantitative understanding of emissions and atmospheric processes altered by human activity, in turn, is necessary for attributing observed changes in atmospheric composition or processes to human activity or natural variation. Climate models able to reproduce concentrations and properties of atmospheric constituents at locations dominated by natural processes will be more likely to correctly distinguish between natural and anthropogenic factors influencing climate than models failing to reproduce these baseline conditions.

The Antarctic aerosol has attracted attention as early as the 1960s, but mainly for exploratory reasons (see Shaw, 1988, for an overview of this period). The first observations with quantitative reliability are probably those of the total particle number concentration $N_{\text {tot }}$ at South Pole Observatory, which started in 1974 and were augmented by observations of the spectral aerosol scattering coefficient $\sigma_{\mathrm{sp}}(\lambda)$ in 1979 (Bodhaine et al., 1986). Already these observations have revealed a few basic characteristics of the central Antarctic aerosol. Firstly, a very stable annual cycle of $N_{\text {tot }}$ with its minimum in winter and its maximum in summer was observed, with a corresponding cycle in $\sigma_{\mathrm{sp}}(\lambda)$, even though the values regularly approached the detection limit of the instruments. Speculations followed (Shaw, 1988) whether the 
$N_{\text {tot }}$ cycle was caused by a corresponding cycle in particulate sulphate concentrations (Cunningham and Zoller, 1981), induced by changing photolytic production of sulphate aerosol in air masses downwelling from the stratosphere (Ito, 1993). The second characteristic is the episodic influence of marine aerosol associated with frontal systems, which affects not only coastal but also inland Antarctic stations (Bodhaine et al., 1987). These marine episodes are characterised by simultaneous peaks in $\sigma_{\mathrm{sp}}(\lambda)$ and the concentration of particleborne sodium. Both annual cycles and episodic marine influence have been confirmed at other stations such as Syowa (Ito, 1985, 1993) and Neumayer (Weller and Lampert, 2008). Seasonal shifts in the particle size distribution were also observed, but only in a qualitative manner due to instrumental limitations in size resolution (Ito, 1993).

Only rather recently has modern instrumentation for measuring the particle number size distribution (PNSD) with high size resolution (Koponen et al., 2003) for performing local closure studies (Virkkula et al., 2006) and measuring particle hygroscopicity (Asmi et al., 2010) been applied in Antarctica, but mostly in the context of summer intensive campaigns. Comprehensive year-round observations of PNSD and optical aerosol properties, as recommended by the WMO Global Atmosphere Watch (GAW) programme, have been reported so far only from the Norwegian Troll station (Hansen et al., 2009; Fiebig et al., 2009) and station Dome C (Järvinen et al., 2013).

In contrast to most previous analyses of annual cycles in the Antarctic aerosol, this study discriminates the aerosol by origin, and focuses only on the baseline component. Observations of $N_{\text {tot }}$, PNSD and aerosol optical properties are set into a context to reveal a common origin of the annual cycle in different properties of the Antarctic baseline aerosol. Modern modelling techniques are used to improve the assessment of the sources of this aerosol. Finally, an attempt at quantifying the Antarctic baseline aerosol annual cycle in a model compatible way is made.

\section{Baseline atmospheric aerosol annual cycle at Troll}

\subsection{Experimental}

The atmospheric aerosol properties observed at Troll Atmospheric Observatory cover a large fraction of the core variables recommended by the WMO GAW programme: particle size distribution, optical properties (scattering and absorption), inorganic chemical composition (until 2011), and column optical depth (see Table 1). For the present analysis, the observations of particle number size distribution (PNSD) by differential mobility particle sizer (DMPS), particle number concentration integrated over the PNSD, $N_{\text {int }}$, and aerosol scattering coefficient, using a TSI 3563 integrating nephelometer, are used. In an auxiliary function, measurements of the aerosol absorption coefficient obtained with a particle soot absorption photometer (PSAP) are also utilised.

The DMPS system is custom-built based on components provided by the Department of Applied Environmental Science at Stockholm University. It uses a Hauke-type differential mobility analyser (DMA) (Reischl, 1991), a closedloop sheath air flow setup controlled by a critical orifice, a $370 \mathrm{MBq}{ }^{63} \mathrm{Ni}$ bipolar sample charger, and a TSI 3010 Condensation Particle Counter (CPC) to detect the particles in the selected size fraction. Sample as well as sheath air flow are calibrated weekly with a flow-standard. The DMPS covers a size range of $33-830 \mathrm{~nm}$ particle diameter $D_{\mathrm{p}}$ with 30 size bins. The raw size bin particle concentrations are inverted to particle number size distributions using the algorithm of Fiebig et al. (2005), which uses the bipolar equilibrium charge probabilities of Wiedensohler (1988). Integrating nephelometer and PSAP are operated according to the GAW aerosol standard operating procedure (GAW, 2011). For the integrating nephelometer, this operating procedure is based on the recommendations of Anderson et al. (1996) and Anderson and Ogren (1998), and includes correction of the angular truncation. The instrument's zero point is measured once per hour, while the span is checked once per week using carbon dioxide of high purity. The PSAP data analysis includes corrections for filter loading and particle scattering, as described by Bond et al. (1999). All instruments receive their sample through a common PM10 inlet with the main pipe entering the observatory container vertically, and sample take-offs to each instrument located centrally in the main inlet pipe.

A significant issue to be taken into account when analysing data collected at Troll is local contamination. The atmospheric observatory was set up at an early stage of developing Troll into a whole-year station when the infrastructure was still less developed. Just to ensure winter access to the atmospheric observatory, it was thought necessary to choose a location only about $200 \mathrm{~m}$ from the main station building. This location is still within reach of diffuse gaseous emissions from the main building by turbulent diffusion (kitchen exhaust, sewage system outgassing), as well as emissions of fossil-fuel driven vehicles. Four indicators are therefore used to flag the data for local contamination: (1) wind direction from contaminated sector (direct contamination); (2) wind speed below $1 \mathrm{~m} \mathrm{~s}^{-1}$ (turbulent diffusion from main station); (3) single scattering albedo $\varpi_{0}<0.8$ (fossil-fuel driven vehicles); and (4) particle number size distribution for $30 \mathrm{~nm}<D_{\mathrm{p}}<40 \mathrm{~nm}$, which is more than 3 times higher than for $100 \mathrm{~nm}<D_{\mathrm{p}}<150 \mathrm{~nm}$ (new particle formation due to diffuse emissions from main station). The contamination criteria are tested based on $1 \mathrm{~min}$ samples ( 6 min for size distribution). The $1 \mathrm{~h}$ averaged data are marked with a respective local contamination flag as soon as they occur within the hour. 
Table 1. Aerosol parameters observed at Troll and instruments used.

\begin{tabular}{ll}
\hline Instrument & Parameter measured \\
\hline $\begin{array}{l}\text { Differential mobility particle sizer (DMPS, custom) } \\
\text { Integrating nephelometer (TSI 3563) }\end{array}$ & $\begin{array}{l}\text { particle number size distribution }(30-800 \mathrm{~nm}) \\
\text { aerosol scattering coefficient }(450,550,700 \mathrm{~nm} \text { wavelength) } \\
\text { aerosol hemispheric backscattering coefficient }(450,550,700 \mathrm{~nm} \text { wavelength) }\end{array}$ \\
$\begin{array}{l}\text { Particle soot absorption photometer (custom) } \\
\text { Sequential air sampler (filter samples, EMEP type) } \\
\text { (discontinued in 2011) }\end{array}$ & $\begin{array}{l}\text { inorganic chemical composition } \\
\text { Precision filter radiometer (PFR, GAW type) }\end{array}$ \\
\hline
\end{tabular}

\subsection{Baseline aerosol annual cycle}

The starting points of the present analysis are the time series of aerosol scattering coefficient $\sigma_{\mathrm{sp}}$ and particle number size distribution (PNSD) collected over the first 5 years of operating Troll Atmospheric Observatory, 2007-2011, which are displayed in Fig. 1. The upper panel depicts the daily averages of $\sigma_{\mathrm{sp}}$ at $550 \mathrm{~nm}$ wavelength over this period, whereas the lower panel shows a colour contour plot of the PNSD. In this type of plot, the $x$ axis holds the time, the logarithmic $y$ axis the particle diameter, and the logarithmic colour code the particle concentration normalized by the logarithmic particle size interval ( $\left.\mathrm{d} N / \mathrm{d} \log D_{\mathrm{p}}\right)$. To give a complete overview, the data in this plot are cleared of instrument malfunctions, but not local contamination.

Probably the most prominent feature in the $\sigma_{\mathrm{sp}}$ time series are the peaks going up to $\sim 10 \mathrm{Mm}^{-1}$, well above the baseline that extends up to $\sim 2 \mathrm{Mm}^{-1}$. The baseline in turn is not a line in the strictest sense, but a band of values, which is due to the fact that $\sigma_{\mathrm{sp}}$ values in this range approach the detection limit of the integrating nephelometer, at around $0.3 \mathrm{Mm}^{-1}$. The scattering peaks are associated with peaks in the PNSD on the upper end of the measured size range. This indicates that these peaks are caused by marine air masses featuring a more pronounced sea spray-generated coarse mode, which is confirmed by trajectory analysis (not shown) and also confirms findings of previous studies (e.g. Bodhaine et al., 1987).

The other prominent feature, the one of interest here, is the annual cycle in the baseline of both $\sigma_{\mathrm{sp}}$ and PNSD. In the Fig. 1 panel showing the $\sigma_{\mathrm{sp}}$ time series, the baseline is visible as a band of values at the lower end of the measured range outside of peaks caused by marine intrusions or local contamination. To underline this annual cycle graphically, the upper panel of Fig. 1 contains also the 4-week running 5th percentile of $\sigma_{\mathrm{sp}}(550 \mathrm{~nm})$ (dark green line).

In the remainder of this article, all data points flagged as locally contaminated have been removed from the analysis. As simple yet numerically precise criterion for selecting baseline aerosol, it is required that $\sigma_{\mathrm{sp}}(550 \mathrm{~nm})$ is smaller than the threshold of 2.5 times the 4-week running 5th percentile of $\sigma_{\mathrm{sp}}(550 \mathrm{~nm})$ (black line in upper panel of Fig. 1). The following questions concerning the baseline aerosol an-

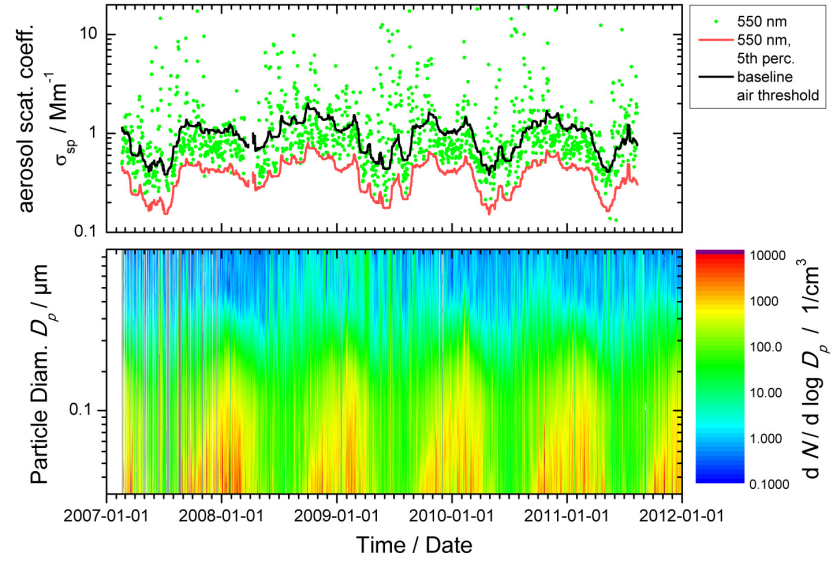

Fig. 1. Troll 2007-2011 time series of aerosol scattering coefficient (550 nm, daily averages, upper panel) and particle number size distribution (PNSD, lower panel). The upper panel also contains the time series of the $550 \mathrm{~nm}$ aerosol scattering coefficient running 4week 5th percentile (light red, based on hourly values) to underline the annual cycle of the baseline aerosol properties. Furthermore, the baseline air mass threshold criterion based on the $550 \mathrm{~nm}$ aerosol scattering coefficient running 4-week 5 th percentile is also plotted (black line). The PNSD, measured by differential mobility particle sizer (DMPS), is shown as a colour contour surface plot with time on the $x$ axis, particle diameter on the logarithmic $y$ axis, and logarithmic colour code for the particle number concentration (normalised by logarithmic size interval). Both data sets are cleared for instrument malfunctions, but not for local contamination.

nual cycle are investigated or, with respect to previous studies, revisited:

- What is the horizontal scale of the baseline aerosol annual cycle?

- Do the annual cycles in baseline $\sigma_{\mathrm{sp}}$ and baseline $\mathrm{PNSD} / N_{\text {tot }}$ have the same physical origin?

- Where do the baseline aerosol air masses originate?

- How does the PNSD vary across the annual cycle?

- How can the baseline aerosol annual cycle be explained? 

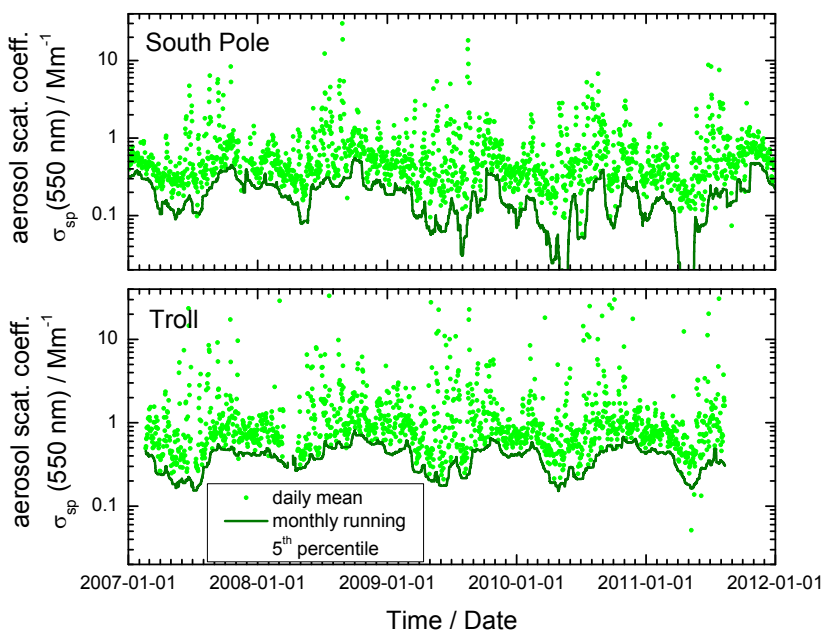

Fig. 2. Time series (2007-2011) of aerosol scattering coefficient daily averages at $550 \mathrm{~nm}$ wavelength measured at the Global Atmosphere Watch stations, South Pole (top panel), and Troll (lower panel). To highlight the annual cycle in the baseline scattering coefficient data, the plots also contain the running 4-week 5th percentiles, which are based on hourly values.

\section{Antarctic baseline aerosol annual cycle: a large-scale phenomenon}

In order to investigate the spatial scale of the baseline aerosol annual cycle observed at Troll, it is necessary to look at observations of $\sigma_{\mathrm{sp}}$ or PNSD at other Antarctic stations. At South Pole Observatory, operated by the US National Oceanic and Atmospheric Administration (NOAA), $N_{\text {tot }}$ has been measured since 1974, and $\sigma_{\mathrm{sp}}$ since 1979, with both time series still ongoing. In Fig. 2, the daily averages of $\sigma_{\mathrm{sp}}$ $(550 \mathrm{~nm})$ measured at Troll for the 2007-2011 period (bottom panel) are compared with the $\sigma_{\mathrm{sp}}(550 \mathrm{~nm})$ daily averages observed at South Pole for the same time period (upper panel). Fig. 3 displays the corresponding time series of $N_{\text {tot }}$ measured with a condensation particle counter (CPC) at South Pole (top panel), and $N_{\text {int }}$, the particle concentration integrated over the DMPS-measured PNSD at Troll station (bottom panel). To underline the annual cycle in the baseline, both panels also contain the running 4-week 5 th percentiles. Even though the baseline extends to still lower $\sigma_{\mathrm{sp}}$ values at South Pole as compared to Troll, it is safe to state that the baseline $\sigma_{\mathrm{sp}}$ and $N_{\text {tot }} / N_{\text {int }}$ values at both stations show the same annual cycle. This conclusion is not affected by the different size ranges covered by $N_{\text {tot }}$ (particle diameters $\left.D_{\mathrm{p}}>14 \mathrm{~nm}\right)$ and $N_{\text {int }}\left(D_{\mathrm{p}}>30 \mathrm{~nm}\right)$ since the comparison is relative. This underlines the corresponding earlier findings for $\sigma_{\mathrm{sp}}$ and $N_{\text {tot }}$ at stations Syowa (Ito, 1985, 1993) and Neumayer (Weller and Lampert, 2008), and also a recent article by Järvinen et al. (2013) discusses the same baseline aerosol annual cycle observed in PNSD measurements performed at Concordia station, Dome C, Antarctica.

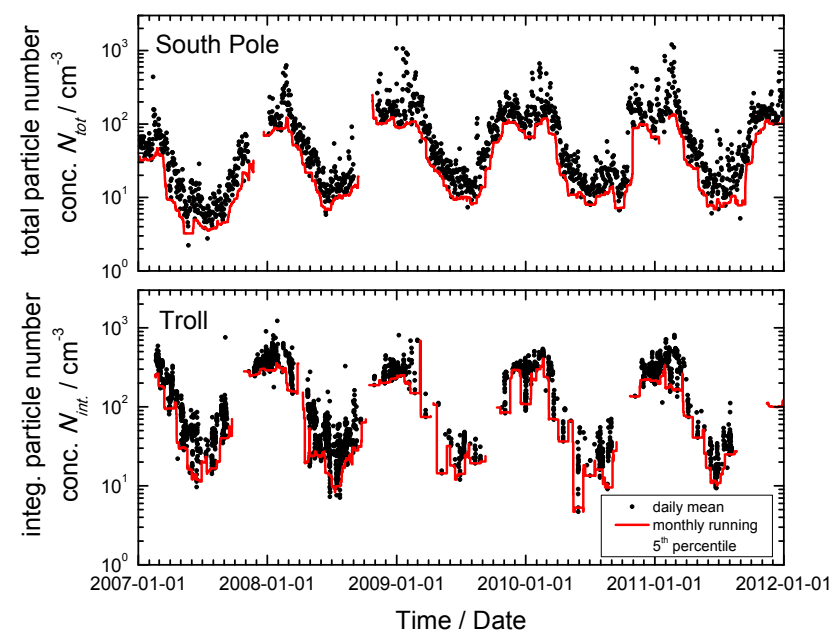

Fig. 3. Time series (2007-2011) of daily averaged total particle number concentration $N_{\text {tot }}$ measured by condensation particle counter (CPC) at South Pole station (top panel, black dots), and corresponding time series of particle number concentration integrated over the PNSD $N_{\text {int }}$ measured by DMPS at Troll station (bottom panel, black dots). To highlight the annual cycle also in the particle number concentration, the plots contain the respective running 4-week 5th percentiles (red lines), which are again based on hourly values.

To put these observations into perspective, the sheer distance between these locations observing the phenomenon needs to be pointed out. Even though Troll station is located $235 \mathrm{~km}$ from the Antarctic coast, the distance to South Pole is still about $2000 \mathrm{~km}$. Troll station and Dome $\mathrm{C}$ are separated by roughly $3100 \mathrm{~km}$, while Dome C is itself located $1670 \mathrm{~km}$ north of South Pole. It can be concluded that the described annual cycle in baseline aerosol properties is a phenomenon common to the whole Antarctic Plateau, with Troll station located on the outskirts.

\section{Annual cycle in physical and optical aerosol properties: a common cause}

Another question to be investigated is whether the annual cycles in baseline aerosol PNSD and $\sigma_{\mathrm{sp}}$ at Troll have the same physical cause, or just happen to be correlated due to other aerosol absorption coefficient reasons. To this end, a Mie scattering code based on the algorithm by Bohren and Huffman (1983) and described in Fiebig et al. (2002) was used to calculate $\sigma_{\mathrm{sp}}$ from the PNSD measured by the DMPS system at the wavelengths provided by the integrating nephelometer. A chemical composition of pure ammonium sulphate was assumed for the calculation. Absorbing components were neglected in the chemical composition since the aerosol absorption coefficient $\sigma_{\text {ap }}$ is below its detection limit for baseline aerosol air masses. 

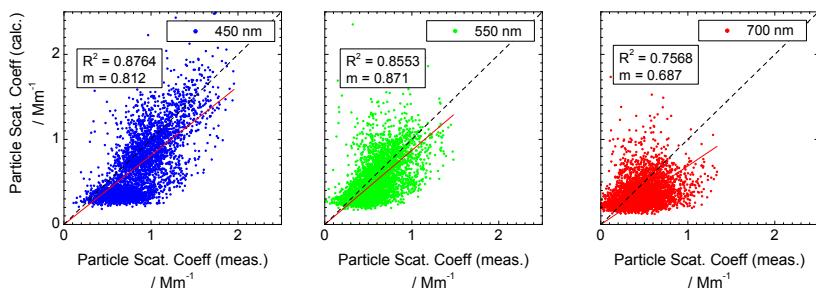

Fig. 4. Scatter plot of the aerosol scattering coefficient measured directly by integrating nephelometer ( $x$ axis), and calculated from the particle number size distribution assuming non-absorbing, spherical particles consisting of ammonium sulphate, one panel for each of the nephelometer wavelengths. Also plotted are the linear regression lines (red solid, intercept fixed at 0 ), including their slope $m$ and the coefficient of determination $R^{2}$, as well as the $1: 1$ line (black dashed).

Figure 4 compares $\sigma_{\mathrm{sp}}$ calculated from the PNSDs with $\sigma_{\mathrm{sp}}$ measured by the integrating nephelometer with scatter plots, one panel for each wavelength provided by the nephelometer. The panels also include the linear regression lines (red solid) with slope $m$ and coefficient of determination $R^{2}$, as well as the $1: 1$ lines (black dashed). The regression line intercept was fixed at 0 since $\sigma_{\mathrm{sp}}$ measured by nephelometer falls below the instrument detection limit when approaching 0 .

For the blue and green wavelengths, $R^{2}$ between measured and calculated $\sigma_{\mathrm{sp}}$ is larger than 0.85 , i.e. more than $85 \%$ of the variation in one variable is explained by the variation in the other. For the red wavelength, $R^{2}$ falls to 0.75 . This can be explained by the fact that the PNSD size range determining $\sigma_{\mathrm{sp}}$ extends to larger particle diameters with increasing wavelength. The PNSD provided by the DMPS system at Troll has an upper limit of $D_{\mathrm{p}}=830 \mathrm{~nm}$. Larger particles are included in $\sigma_{\mathrm{sp}}$ measured by the nephelometer, but not in $\sigma_{\mathrm{sp}}$ calculated from the PNSD. The same line of argument also explains that the regression line slope is smaller than 1 , and that the regression line slope for the red wavelength is significantly smaller than for blue and green. In addition, the assumption on the refractive index made in the calculation may contribute to the regression slope differing from 1 . A variation of the real part refractive index causes a change in scattering coefficient on the order of $13 \%$ (Fiebig et al., 2002).

Nevertheless, the analysis shows for the first time that it is safe to state that annual cycles in baseline $\sigma_{\mathrm{sp}}, N_{\mathrm{tot}} / N_{\mathrm{int}}$, and PNSD observed at Troll and other Antarctic atmospheric observatories are characteristics of the same underlying physical process.

\section{Origin of baseline air masses at Troll}

For investigating the origin of the baseline aerosol air masses at Troll, the Lagrangian particle dispersion model FLEX-
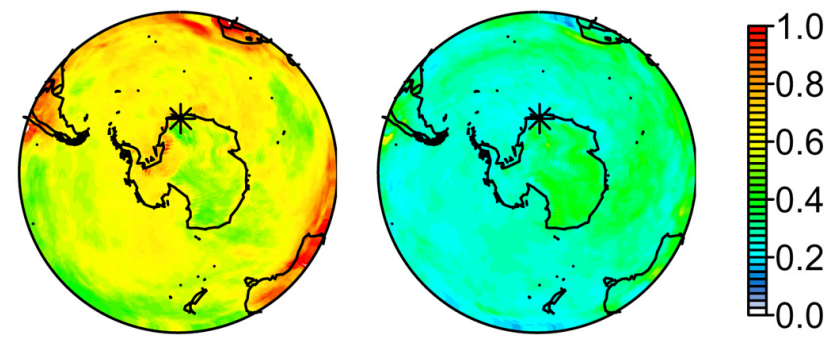

Fig. 5. Using the 2007-2011 FLEXPART calculations for all plumes going backward from Troll, the above plots show the relative Southern Hemisphere footprints for non-baseline (left panel) and baseline (right panel) air cases, where relative means relative to the mean footprint. The footprint is the relative probability of backward plume air being located in the lowermost $100 \mathrm{~m}$ of the atmosphere in a given location on the map. The location of Troll station is marked by an asterisk.

PART (Stohl et al., 1998, 2005), driven with meteorological data from the European Centre for Medium-Range Weather Forecast (ECMWF), was used to calculate 20-day backward plumes for the air masses arriving at Troll Atmospheric Observatory. Based on the years 2007-2011, Fig. 5 shows maps of the footprint of these plumes, i.e. the likelihood of the backward transported particles to reside in the lowest $100 \mathrm{~m}$ of the atmosphere as a function of location. The footprints have been normalised by the mean footprint, and Fig. 5 distinguishes between non-baseline (left panel) and baseline (right panel) cases using the definition given in Sect. 2.2.

From Fig. 5, it is obvious that the Troll baseline aerosol air masses resided over the Antarctic continent within the 20-day period prior to arrival at Troll. However, there is a circle around the Antarctic continent where the footprint of baseline air masses is small. This indicates that these baseline air masses generating the footprint over the Antarctic continent descended from aloft. The right panel of Fig. 5 also shows where these descending baseline air masses originated. There is one ring of increased footprint at southern mid-latitudes, and another one in the tropics. These are obviously the regions where the Troll baseline air is uplifted from the boundary layer for subsequent southward transport and descend over the Antarctic continent, a turnover taking well over 10 days. The footprint of the Troll non-baseline air, depicted in the left panel of Fig. 5, reconfirms these findings. The non-baseline air footprint is depleted over the Antarctic continent, but enhanced in the marine boundary layer of the Southern Ocean immediately north of Troll station, a region abundant with aerosol precursor gases.

The Antarctic continent is a region of subsiding air masses and essentially free of local sources of primary aerosol and secondary aerosol precursor gases. The recent finding of particle generation over Antarctic meltwater ponds due to precursor emissions from cyanobacteria (Kyrö et al., 2013) does not affect this fact. The spatial extend of these ponds is too 


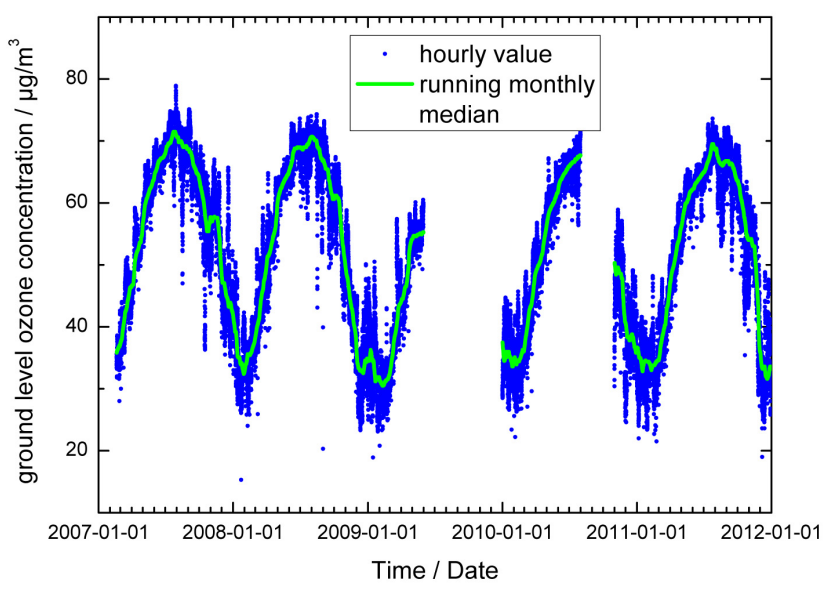

Fig. 6. Time series of atmospheric ground-level ozone concentration (hourly averages) at Troll in the time period 2007-2011. Also plotted is the running 4-week median (green line) to extract the annual cycle in the ozone concentration.

small to explain a phenomenon that spans the whole central Antarctic continent, especially since the annual cycle is observed also in the centre of the Antarctic continent where meltwater ponds are absent. It can therefore be stated that the processes causing the annual cycle in Antarctic baseline aerosol must be happening within the air mass without external additions of aerosol precursor gases.

To test this model-based finding further, the concentrations of boundary layer ozone measured at Troll observatory were considered. Over Antarctica, the tropopause descends to rather low altitudes, in winter sometimes even to the ground (Roscoe, 2004). If the baseline aerosol air masses in fact subside from aloft, they should reflect the high stratospheric ozone concentrations at least to some degree as compared to non-baseline air. When performing such an analysis, it needs to be taken into account that the annual cycle of Antarctic boundary layer ozone is determined not only by transport from the stratosphere, but also by destruction via hydrogen peroxide, which is generated photochemically (Ayers et al., 1992). This causes a depletion of Antarctic boundary layer ozone proportionally to solar insolation. The resulting annual cycle is reflected in the boundary layer ozone time series collected at Troll (see Fig. 6). This boundary layer ozone depletion process however affects all air masses equally independent of origin. When comparing ozone concentrations in baseline and non-baseline air, this annual cycle therefore needs to be filtered out.

To this end, the hourly averaged ozone data were separated into baseline and non-baseline cases after clearing locally contaminated data. For each data point, the difference to the 4 -week running 25 th, 50 th, and 75 th percentiles were calculated, and the differences were averaged separately for baseline and non-baseline cases. From the result displayed in Fig. 7, it can be deduced that the average baseline ozone
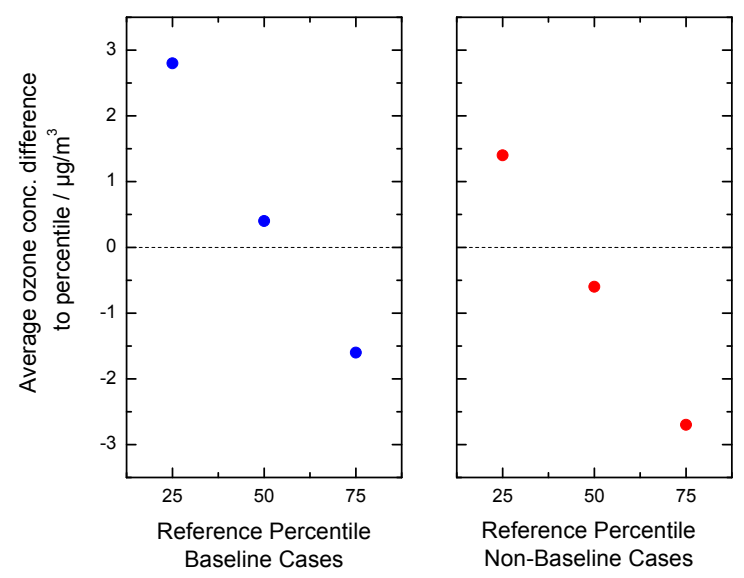

Fig. 7. This graph uses the baseline air mass criterion based on the aerosol scattering coefficient to divide the Troll ozone data into two sub-data sets: (1) baseline air mass cases (left panel); (2) nonbaseline air mass cases (right panel). For each hourly averaged data point in the two sub-data sets, the difference to the 4-week running 25th, 50th, and 75th percentiles was calculated. The plot contains the averages of these differences for the two data subsets. This is done to investigate whether the baseline cases have a systematically higher ozone concentration than the non-baseline cases, while at the same time removing the annual cycle in the ozone data caused by photochemical destruction. Events of local contamination have been filtered out before the analysis.

concentration corresponds to percentile $56 \pm 4.2$, whereas the average non-baseline ozone concentration corresponds to percentile $42 \pm 1$. The ozone data thus supports the finding of the FLEXPART backward plume analysis that the baseline air masses observed at Troll are subsiding air masses and, at least to some degree, influenced by ozone-rich stratospheric air.

The picture is consistent with the findings of Roscoe (2004), who describes a pronounced downward transport across the central Antarctic tropopause due to a weak tropopause inversion, subsidence in the stratosphere, and surface level suction to resupply katabatic winds draining the central Antarctic boundary layer, which is more pronounced in winter than in summer. The Antarctic transport climatology by Stohl and Sodemann (2010) also supports this view. However, it seems unlikely that the central Antarctic baseline air originates purely in the lower stratosphere. Yang et al. (2012) report on a plume found at $11.5 \mathrm{~km}$ altitude at $86^{\circ} \mathrm{S}$ over the central Antarctic continent during a flight of the NASA DC-8 aircraft. This aged mixed-pollution plume originated from lower latitude pollution and was uplifted in a frontal conveyer belt. It therefore seems to be a more realistic picture that free tropospheric air of lower-latitude origins is sandwiched between tropopause and ground while being transported to central Antarctica. There, the whole freetropospheric and lower stratospheric column would be subject to large-scale subsidence. The central Antarctic baseline 

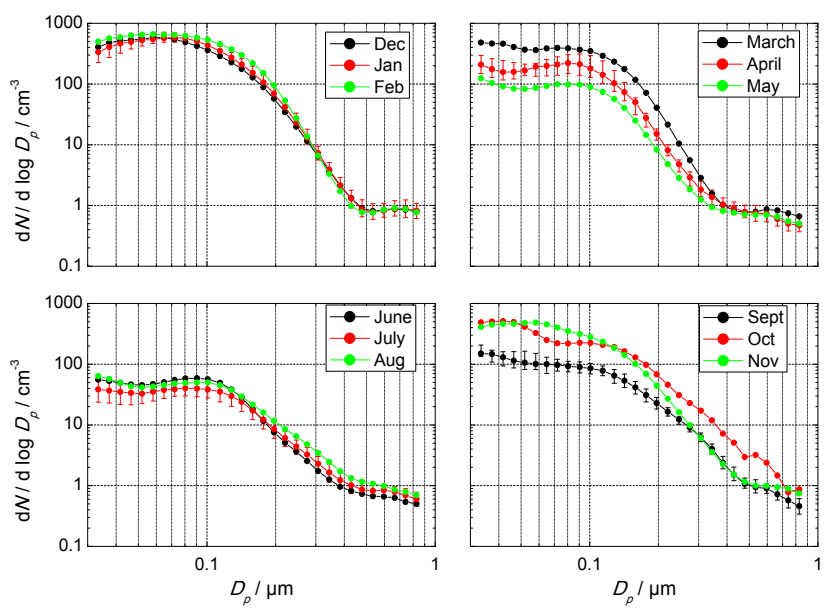

Fig. 8. Monthly average particle number size distributions (PNSDs) based on the 2007-2011 data measured at Troll for all baseline air masses, as determined by the aerosol scattering coefficient criterion described in the text. The PNSDs are grouped by season in panels; summer top left, autumn top right, winter bottom left, spring bottom right. The 25th and 75th percentiles are plotted as whiskers to indicate the atmospheric variability.

air would then be a mixture of these, still rather pristine, free tropospheric and lower stratospheric air masses. In either case, we are dealing with aged air that is free of recent external additions of aerosol precursor gases, and that likely underwent cleaning by cloud processing and rainout while being uplifted.

\section{The antarctic baseline aerosol annual cycle in particle size distribution and particle volume concentration}

After establishing that the baseline aerosol light scattering annual cycle at Troll is associated with a corresponding cycle in the PNSD, and that these cycles likely reflect properties of free tropospheric and lower stratospheric air masses subsiding over the whole central Antarctic region, it is instructive to investigate which differences in the PNSD cause this annual cycle. To this end, Fig. 8 shows the monthly average baseline PNSDs based on the data obtained from the DMPS at Troll for 2007-2011 after the data have been cleared for local contamination. The monthly PNSD graphs are organised by season into 4 panels (summer top left, autumn top right, winter bottom left, spring bottom right). The one standard deviation variability is also plotted for one PNSD per panel as typical value, but not for all PNSDs to improve readability.

It is most instructive to compare first the PNSDs for summer (top left panel) and winter (bottom left panel). For these seasons, the variability of the baseline PNSD is remarkably small, i.e. the deviations between the months are small. The summer PNSDs are dominated by a log-normal "Aitken mode" peaking at particle diameters $D_{\mathrm{p}}$ between 60 and
$70 \mathrm{~nm}$. A log-normal accumulation mode can be discerned peaking at $D_{\mathrm{p}}$ between $100-150 \mathrm{~nm}$, but almost vanishes in the large particle shoulder of the Aitken mode. According to Jaenicke (1980, Fig. 2, background aerosol case), particles in the Aitken mode size range have an atmospheric lifetime on the order of up to 10 days under background aerosol conditions, and thus must have been formed from the gas-phase during this time period. In Sect. 5, it has been shown that the Troll baseline aerosol can be seen as a mixture of descending free tropospheric and lower stratospheric air masses that has passed through regions void of emissions of condensable gas-phase species. The particles in the Aitken mode size range dominating the Troll baseline aerosol in summer thus must have been formed within their air mass.

The winter baseline aerosol particle size distribution at Troll is characterised by number concentrations about an order of magnitude lower than in summer, while the variability between the winter months is almost as low as in summer. The dominating log-normal mode is centred in the accumulation mode size range at about $90 \mathrm{~nm}$ particle diameter, while particles in the Aitken mode size range are strongly depleted as compared to summer. Particles in the accumulation mode size range are the result of coagulation between Aitken mode particles and between Aitken and accumulation mode particles (Jaenicke, 1980). The combination of a dominant accumulation mode and almost absent Aitken mode is the result of extended self-processing of the winter baseline aerosol at Troll without any significant formation of new particle mass. Particle growth through cloud processing may also occur, but will be of little importance due to the large-scale subsidence of air over central Antarctica. The self-processing seen in the winter baseline aerosol at Troll probably partly reflects properties of descending lower stratospheric air and the wellknown fact that exchange between the Antarctic stratosphere and the stratosphere at higher latitudes is inhibited by the Antarctic winter circumpolar vortex (e.g. Holton, 1992), and that photochemical aerosol production is inhibited in winter due to darkness.

The PNSDs observed in the spring and autumn baseline aerosol at Troll represent a gradual transition between the states of summer and winter.

\section{Antarctic baseline aerosol annual cycle: a photooxidation-limited process?}

In the last section, it was discussed that the summer baseline aerosol PNSD at Troll is dominated by particles in the Aitken mode size range. These particles are formed from the gasphase within a few days prior to measurement, despite the absence of any external sources of condensible gases along the transport pathway. The transport pathway was shown to go through the free troposphere or lower stratosphere and descend over the central Antarctic continent. A possible explanation for the formation of particle mass would be 


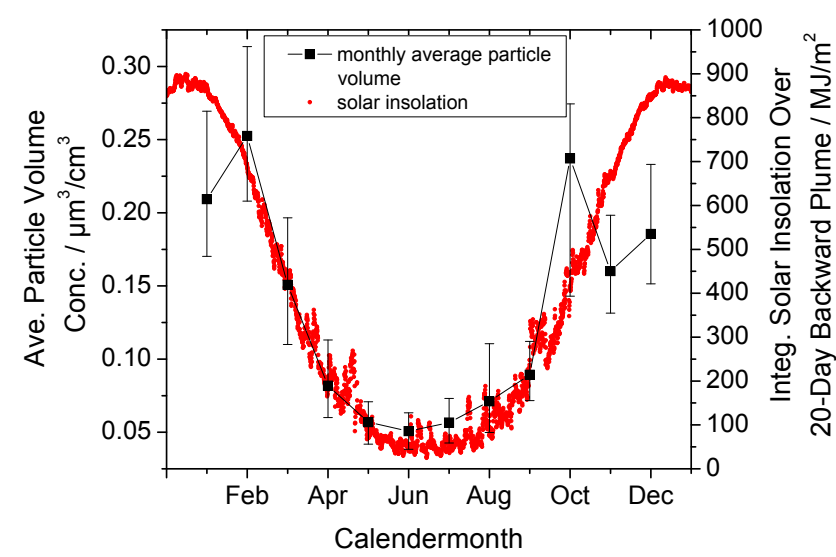

Fig. 9. Monthly average particle volume concentration (integrated over particle size) based on the particle number size distributions in baseline air masses observed at Troll in the 2007-2011 time period (black squares). Also plotted for comparison is the average solar insolation on the air masses arriving at Troll integrated along the 20-day backward plume, as calculated by FLEXPART for the year 2010.

the photochemical oxidation of precursor gases into species with low volatility, with subsequent condensation onto the particle-phase. Due to the strong annual cycle of insolation at polar latitudes, this photochemical production of aerosol volume, and thus the aerosol volume itself, should then also have an annual cycle.

In Fig. 9, the monthly average total particle volume, obtained from integrating particle volume over the hourly baseline PNSDs measured at Troll over the 2007-2011 period, is plotted after the data have been cleared for local contamination. It is rather easy to detect that the baseline aerosol total particle volume indeed shows the predicted annual cycle. This finding was confirmed by Järvinen et al. (2013), who found the same annual cycle in the total particle volume at station Dome C, Antarctica.

To support the hypothesis further, the backward plume calculations obtained with the FLEXPART model are used to calculate the average integrated top-of-atmosphere solar insolation along the path of the 20-day backward plumes. The calculation is based on particle positions as a function of time and yields an upper limit of the insolation, but due to subsiding air in central Antarctica, the "cloud-free" assumption is not completely unrealistic. The exact length of the backward plume has little influence on the result as long as the whole transport path with strong variations in latitude is covered. For an initial comparison, the integrated solar insolation is also plotted in Fig. 9 on its own axis for the year 2010. Indeed, total particle volume and the insolation the air mass received during the 20 days prior to measurement seem to be highly correlated, showing a synchronous annual cycle. During the austral summer, the correlation seems to be slightly more noisy. Possible reasons include more local ac-

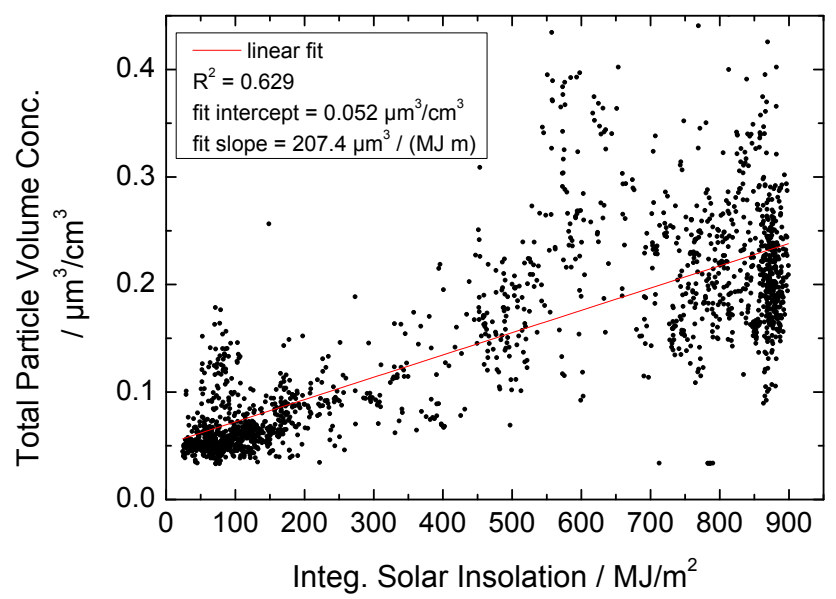

Fig. 10. Graph investigating the correlation between the particle volume concentration ( $y$ axis, integrated over particle size) and the solar insolation integrated over the 20-day backward plume ( $x$ axis), as calculated by FLEXPART. Also plotted is the linear regression line, including slope, intercept, and coefficient of determination.

tivity around the station in summer, which is difficult to filter out with the local contamination markers used, and also depletion of oxidisable gas-phase material in the air mass and thus condensible vapours caused by the strong solar insolation.

Of course, the proper way to investigate a suspected correlation between two properties is by using a scatter plot. For the baseline aerosol air masses arriving at Troll, Fig. 10 shows such a scatter plot for aerosol particle volume and 20day integrated insolation prior to arrival. The plot is based on the individual 3-hourly averages of the baseline aerosol air masses cleared for local contamination. The correlation of the two properties is plainly discernable despite some noise, which is probably largely due to transport model errors and uncertainties of the input wind fields to the dispersion model, and also variations in aerosol precursor gas composition. The coefficient of determination $R^{2}=0.63$ confirms clearly that the correlation is significant. The slope of the regression line amounts to a photooxidation-induced production of aerosol particle volume of $207 \pm 4 \mu \mathrm{m}^{3} /(\mathrm{MJ} \mathrm{m})$ in the air masses descending into the boundary layer over the central Antarctic continent. This number needs to be seen as a lower limit, since the DMPS system misses some particle volume on the upper end of the size range. Also, the uncertainty on the stated aerosol volume production rate reflects only the uncertainty of the fit. Other sources of uncertainty include at least the ECMWF wind fields driving the FLEXPART transport model, cloud cover, and the chemical nature of aerosol precursor gases. Nevertheless, the data are consistent with assuming that the process is limited by the photooxidation capacity, maybe apart from periods in summer when available precursor gases may be exhausted. 
It is instructive to put these findings into their context of larger atmospheric transport patterns. The air masses descending over the central Antarctic continent from the lower stratosphere to the surface are part of a circulation pattern where, in the meridional projection, air is injected into the stratosphere in the Intertropical Convergence Zone (ITCZ), transported poleward, and descends into the UT/LS (upper troposphere and lower stratosphere) region and the troposphere in the polar regions (e.g. Holton, 1992, chapter 12). Due to the absence of any significant sources of oxidisable gas-phase species on this transport pathway, it needs to be assumed that the precursor gases for the observed photooxidative production of aerosol volume in these air masses are already present when the air is transported upward in the ITCZ by tropical convective anvils. A candidate group for these oxidisable gas-phase species are organic vapours of low water solubility that survive wet removal in the tropical convective anvils. In fact, such species have been found in Antarctic aerosol samples (Kawamura et al., 1996). The air masses descending from the free troposphere to the central Antarctic surface likely have a whole spectrum of origins. The air masses observed by Yang et al. (2012) at $11.5 \mathrm{~km}$ altitude at $86^{\circ} \mathrm{S}$ were uplifted from the Southern Ocean marine boundary layer by a frontal conveyer belt, but apparently also contained anthropogenic and biomass burning emissions. Aerosol precursor species in this air mass could therefore consist of sulphate compounds of marine origin in addition to organic compounds. This transport pathway of marine sulphate compounds to the central Antarctic free troposphere by frontal conveyer belts was also previously indicated by Ito (1993). The nature of the photooxidation products entering the particle phase in Antarctic free tropospheric and lower stratospheric air could be determined with dedicated filter samples using a sampler selective for baseline air. However, long sampling intervals required for pristine Antarctic air and local contamination at Troll make this effort currently unfeasible.

Another aspect worth noting concerns the fact that the observed photooxidation-induced production of aerosol particle volume in central Antarctic free tropospheric and lower stratospheric air seems to be limited by photooxidative capacity at least during large parts of the year. This observation is non-trivial since Antarctic air is commonly considered to be among the most pristine on the globe, and therefore a shortage in oxidisable gas-phase species as compared to the photooxidative capacity of the atmosphere could have been expected. Also, the correlation between aerosol particle volume and insolation received by the air parcel holds even though the nature of the precursor species appears to be rather diverse. These two facts, i.e. limitation of the process by photooxidative capacity and robustness against a variety of precursor species involved, leaves room for the hypothesis that the photooxidative aerosol volume production rate found here for Antarctic free tropospheric/lower stratospheric air may have a considerably wider range of application.

\section{Conclusions and outlook}

The annual cycles detected in the baselines of aerosol scattering coefficient $\sigma_{\mathrm{sp}}$, total particle number concentration $N_{\text {tot }}$, and particle number size distribution (PNSD) observed at Troll Atmospheric Observatory, Antarctica, are used as a starting point for (re-)investigating the origin of these baseline aerosol air masses and the cause of the annual cycle. By use of Mie theory, it is demonstrated that the annual cycles in $\sigma_{\mathrm{sp}}$ and $N_{\text {tot }}$ are induced by the corresponding cycle in the PNSD, i.e. all cycles have the same underlying cause. By comparison with $\sigma_{\mathrm{sp}}$ and $N_{\text {tot }}$ data collected at South Pole Observatory, and PNSD data collected at station Dome C, it is shown that the annual cycle observed in baseline aerosol properties at Troll is in fact a large-scale phenomenon common to central Antarctic air masses.

By consulting backward plume calculations with the Lagrangian transport model FLEXPART for the baseline air masses arriving at Troll, it is established that these air masses descend from aloft, i.e. they are not the result of transport of marine air from the adjacent Southern Ocean. Analysing the concentrations of boundary layer ozone at Troll suggests that the baseline air masses are influenced in part by lower stratospheric air, whereas literature shows influence of the free tropospheric column. The central Antarctic baseline air can therefore be considered a mixture of descending free tropospheric and lower stratospheric air. The PNSD in summer central Antarctic baseline air is characterised by a dominant Aitken mode of particles, peaking at $D_{\mathrm{p}}$ between $60-70 \mathrm{~nm}$, and formed within a matter of days prior to observation. In the corresponding winter baseline air masses, the Aitken mode is absent, overall particle concentrations are an order of magnitude lower than in summer, and the PNSD is dominated by an accumulation mode peaking at $D_{\mathrm{p}}$ about $90 \mathrm{~nm}$, indicating extended self-processing by coagulation.

Investigating the formation of particle volume in the summer central Antarctic baseline aerosol further, an annual cycle in the total particle volume in these air masses is discovered that correlates with the annual cycle of the integrated insolation these air masses receive over the 20-day period prior to observation. The process of formation of aerosol particle mass induced by photooxidation seems to be limited by sunlight, not by availability of oxidisable gas-phase aerosol precursor substances. The photooxidative particle volume formation rate in central Antarctic baseline air is determined to $207 \pm 4 \mu^{3} /(\mathrm{MJ} \mathrm{m})$.

The potential uses of these results extend, e.g. to the quantification of the natural versus anthropogenic aerosol climate effects. The Antarctic lower stratospheric aerosol is part of a large-scale circulation pattern, where boundary layer air is injected into the lower stratosphere by convection in the ITCZ, transported poleward in the stratosphere, and descends to the troposphere over the poles. The polar free troposphere also contains aged uplifted marine air, potentially including continental pollution as well. The observed photooxidative 
production of aerosol volume in these air masses is part of this mostly natural process. The correct reproduction of this process in climate models can therefore serve as a benchmark for correct quantification of this natural aerosol process, improving the distinction of natural vs. anthropogenic aerosol climate effects, at least for Antarctica.

Furthermore, the observed production of aerosol particle volume in Antarctic baseline air seems to be mostly limited by photooxidative capacity, even though a limitation by oxidisable precursor gases could be imagined in these pristine air masses. This leaves room for further research as to whether the observed photooxidative particle volume formation rate is applicable also to other regions of the atmosphere.

Acknowledgements. This research has been supported by the Norwegian Antarctic Research (NARE) programme, as well as the European Science Foundation/Norwegian Research Council funded project CLimate IMpacts of Short-Lived pollutants In the Polar region (CLIMSLIP).

Edited by: V.-M. Kerminen

\section{References}

Anderson, T. L. and Ogren, J. A.: Determining Aerosol Aerosol Radiative Properties Using the TSI 3563 Integrating Nephelometer, Aerosol Sci. Tech., 29, 57-69, 1998.

Anderson, T. L., Covert, D. S., Marshall, S. F., Laucks, M. L., Charlson, R. J., Waggoner, A. P., Ogren, J. A., Caldow, R., Holm, R. L., Sem, F. R. Q. J., Wiedensohler, A., Ahlquist, N. A., and Bates, T. S.: Performace Characteristics of a High-Sensitivity, ThreeWavelength, Total Scatter / Backscatter Nephelometer, J. Atmos. Ocean. Tech., 13, 967-986, 1996.

Asmi, E., Frey, A., Virkkula, A., Ehn, M., Manninen, H. E., Timonen, H., Tolonen-Kivimäki, O., Aurela, M., Hillamo, R., and Kulmala, M.: Hygroscopicity and chemical composition of Antarctic sub-micrometre aerosol particles and observations of new particle formation, Atmos. Chem. Phys., 10, 4253-4271, doi:10.5194/acp-10-4253-2010, 2010.

Ayers, G. P., Penkett, S. A., Gillett, R. W., Bandy, B., Galbally, I. E., Meyer, C. P., Elsworth, C. M., Bentley, S. T., and Forgan, B. W.: Evidence for photochemical control of ozone concentrations in unpolluted marine air, Nature, 360, 446-449, doi:10.1038/360446a0, 1992.

Bodhaine, B. A., Deluisi, J. J., Harris, J. M., Houmere, P., and Bauman, S.: Aerosol measurements at the South Pole, Tellus, 38, 223-235, 1986

Bodhaine, B. A., Deluisi, J. J., Harris, J. M., Houmere, P., and Bauman, S.: PIXE analysis of south pole aerosol, Nucl. Instrum. Meth. B, 22, 241-247, 1987.

Bohren, C. F. and Huffman, D. R.: Absorption and Scattering of Light by Small Particles, John Wiley \& Sons, Inc., 1983.

Bond, T. C., Anderson, T. L., and Campbell, D.: Calibration and Intercomparison of Filter-Based Measurements of Visible Light Absorption by Aerosols, Aerosol Sci. Tech., 30, 582-600, 1999.

Cunningham, W. C. and Zoller, W. H.: The chemical composition of remote area aerosols, J. Aerosol Sci., 12, 367-384, 1981.
Fiebig, M., Petzold, A., Wandinger, U., Wendisch, M., Kiemle, C., Stifter, A., Ebert, M., Rother, T., and Leiterer, U.: Optical closure for an aerosol column: method, accuracy, and inferable properties, applied to a biomass burning aerosol and its radiative forcing, J. Geophys. Res., 107, LAC 12-1-LAC 12-15, doi:10.1029/2000JD000192, 2002.

Fiebig, M., Stein, C., Schröder, F., Feldpausch, P., and Petzold, A.: Inversion of data containing information on the aerosol particle size distribution using multiple instruments, J. Aerosol. Sci., 36, 1353-1372, 2005.

Fiebig, M., Lunder, C. R., and Stohl, A.: Tracing biomass burning aerosol from South America to Troll Research Station, Antarctica, Geophys. Res. Lett., 36, L14815, doi:10.1029/2009GL038531, 2009.

GAW, 2011: WMO/GAW Standard Operating Procedures for In-situ Measurements of Aerosol Mass Concentration, Light Scattering and Light Absorption, Tech. rep., World Meteorological Organization, http://www.wmo.int/pages/prog/arep/gaw/ documents/FINAL_GAW_200_web.pdf, 2011.

Hansen, G., Aspmo, K., Berg, T., Edvardsen, K., Fiebig, M., Kallenborn, R., Lunder, C. R., Stebel, K., Schmidbauer, N., Solberg, S., Wasseng, J. H., and Yttri, K.-E.: Atmospheric Monitoring at the Norwegian Antarctic Station Troll: Measurement Programme and First Results, Polar Res., 28, 353-363, doi:10.1111/j.17518369.2009.00134.x, 2009.

Holton, J.: An introduction to dynamic meteorology, International Geophysics Series, Vol. 48, Academic Press, Incorporated, San Diego, New York, Boston, London, Sydney, Tokyo, Toronto, 1992.

Ito, T.: Study of background aerosols in the Antarctic troposphere, J. Atmos. Chem., 3, 69-91, 1985.

Ito, T.: Size Distribution of Antarctic submicron aerosol, Tellus, 45, 145-159, 1993.

Jaenicke, R.: Natural Aerosols, Ann. NY Acad. Sci., 317-329, 1980.

Järvinen, E., Virkkula, A., Nieminen, T., Aalto, P. P., Asmi, E., Lanconelli, C., Busetto, M., Lupi, A., Schioppo, R., Vitale, V., Mazzola, M., Petäjä, T., Kerminen, V.-M., and Kulmala, M.: Seasonal cycle and modal structure of particle number size distribution at Dome C, Antarctica, Atmos. Chem. Phys., 13, 7473-7487, doi:10.5194/acp-13-7473-2013, 2013.

Kawamura, K., Seméré, R., Imai, Y., Fujii, Y., and Hayashi, M.: Water soluble dicarboxylic acids and related compounds in Antarctic aerosols, J. Geophys. Res., 101, 18721-18728, 1996.

Koponen, I. K., Virkkula, A., Hillamo, R., Kerminen, V.-M., and Kulmala, M.: Number size distributions and concentrations of the continental summer aerosols in Queen Maud Land, Antarctica, J. Geophys. Res., 108, 4587, doi:10.1029/2003JD003614, 2003.

Kyrö, E.-M., Kerminen, V.-M., Virkkula, A., Dal Maso, M., Parshintsev, J., Ruíz-Jimenez, J., Forsström, L., Manninen, H. E., Riekkola, M.-L., Heinonen, P., and Kulmala, M.: Antarctic new particle formation from continental biogenic precursors, Atmos. Chem. Phys., 13, 3527-3546, doi:10.5194/acp-13-3527-2013, 2013.

Reischl, G. P.: Measurement of Ambient Aerosols by the Differential Mobility Analyzer Method: Concepts and Realization Criteria for the Size Range Between 2 and $500 \mathrm{~nm}$, Aerosol Sci. Tech., 14, 5-24, 1991. 
Roscoe, H. K.: Possible descent across the "Tropopause" in Antarctic winter, Adv. Space Res., 33, 1048-1052, 2004.

Shaw, G. E.: Antarctic Aerosols: A Review, Rev. Geophys., 26, 89112,1988

Stohl, A. and Sodemann, H.: Characteristics of atmospheric transport into the Antarctic troposphere, J. Geophys. Res., 115, D02305, doi:10.1029/2009JD012536, 2010.

Stohl, A., Hittenberger, M., and Wotawa, G.: Validation of the Lagrangian particle dispersion model FLEXPART against large scale tracer experiment data, Atmos. Environ., 32, 4245-4264, 1998.

Stohl, A., Forster, C., Frank, A., Seibert, P., and Wotawa, G.: Technical note: The Lagrangian particle dispersion model FLEXPART version 6.2, Atmos. Chem. Phys., 5, 2461-2474, doi:10.5194/acp-5-2461-2005, 2005.

Virkkula, A., Koponen, I. K., Teinilä, K., Hillamo, R., Kerminen, V.-M., and Kulmala, M.: Effective real refractive index of dry aerosols in the Antarctic boundary layer, Geophys. Res. Lett., 33, L06805, doi:10.1029/2005GL024602, 2006.
Weller, R. and Lampert, A.: Optical properties and sulfate scattering efficiency of boundary layer aerosol at coastal Neumayer Station, Antarctica, J. Geophys. Res., 113, D16208, doi:10.1029/2008JD009962, 2008.

Wiedensohler, A.: An Approximation of the Bipolar Charge Distribution for Particles in the Submicron Size Range, J. Aerosol Sci. 19, 387-389, 1988.

Yang, M. Y. M., Vay, S. A., Stohl, A., Choi, Y., Diskin, G. S., Sachse, G. W., and Blake, D. R.: Chemical composition of tropospheric air masses encountered during high altitude flights $(11.5 \mathrm{~km})$ during the 2009 fall Operation Ice Bridge field campaign, J. Geophys. Res., 117, D17306, doi:10.1029/2012JD017858, 2012. 